ARTICLE

\title{
Review of Character Strengths Matter - How to Live a Full Life, edited by Shannon Polly and Kathryn Britton
}

\author{
Denise Quinlan
}

\section{Overview}

Character Strengths Matter is a compilation volume of brief articles about each of the 24 character strengths of the Values in Action (VIA) classification of character strengths, plus a section on applying strengths in different contexts. The editors, Shannon Polly and Kathryn Britton, have two clear purposes for this book: to help readers learn about and use character strengths to live a 'full life' and to raise funds for the Christopher Peterson Memorial Fellowship at the University of Pennsylvania. The premise for the book is that that using one's character strengths in service of self and others across one's life domains will contribute to a pleasant, engaged, and meaningful life. This is not a theoretical or research-focused book. Dedicated to using strengths in daily life, this book provides a smorgasbord of stories, reflections, ideas and tips. Its strength lies in the variety of the content and the playfulness of its approach. Like any good smorgasbord, you aren't likely to want everything that's on offer - but you should be able to find something that's novel, interesting and satisfying.

\section{Who is Strengths Matter for?}

The book is a very readable compilation suitable for those who are not familiar with the strengths approach. It introduces the concept of strengths, outlines the development of the VIA classification, the benefits of using strengths, and a process for doing that. It is not intended as an overview of strengths research or practice, and would not stand alone as an introduction for someone wanting to introduce the strengths approach to a workplace or education setting. However, it might encourage them to read further.

For those already familiar with the VIA, the chapters offer a series of individual perspectives on each strength, plus reflections on applying strengths in the workplace, with children and disadvantaged youth, and even on vacation. As it includes the contributions of over 50 authors, even those familiar with the VIA strengths are likely to find something new here.

\section{Strengths awareness, exploration and action}

Originally published online at Positive Psychology News (PPND), the articles have been adapted for publication and the authors have added two features that provide continuity and interest. The inclusion of five actions to build each strength provides a unifying thread that is drawn through the book. These strengths building actions have a consistent perspective as they are all drawn from Tayyab Rashid's online resource Building Your Strengths. This helps to anchor what could otherwise be a very disparate set of voices.

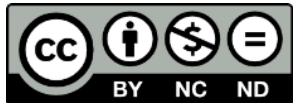

Copyright belongs to the author(s) www.internationaljournalofwellbeing.org 
The other innovation that lifts the volume is the inclusion of poetry and prose that embodies each strength. The variety of pieces ensures that there will be something thought-provoking and meaningful for most readers (and a few that you might skip). Shannon Polly puts the case in the introduction for reading these passages aloud as a way of acting 'as if' we possess the strength being demonstrated. She challenges the reader to take on a role and explore it, and to 'try on' a new way of behaving. My initial response was similar to being asked to participate in the first interactive activity of a seminar - a reluctant, 'do I have to'? My commitment to reviewing overcame reluctance however, and I can report that this was at times an engaging and moving activity (Churchill and Chief Sitting Bull's speeches) and at other times I didn't connect with the prose. However, I would still rate it a worthwhile activity. The world has a lot of 'how to' manuals designed to take us from A to B in the shortest space and time possible. I welcome a book that offers to be a companion on some interesting detours and doesn't expect me to follow every suggestion.

The book's approach draws on Ryan Niemiec's three step process for strengths development: awareness, exploration, and action. A curious reader can follow the links to complete the VIA survey online to build awareness of their strengths. Each strength chapter offers exploration of a strength, and a brief section on applying strengths offers suggestions and warnings about using strengths in the workplace and other settings. The concept of signature strengths and suggestions for using them in a chapter by Niemiec conclude the book.

The strengths of this volume lie in the diversity of voices speaking about strengths, the novel approach of including poetry or prose readings for each strength, and the range of strategies suggested. Chris Peterson once told me that the problem with many academic reviewers was that they spent most of their time criticising what the researcher didn't do, rather than focusing on what they chose to do and determining if they did that well. Polly and Britton have chosen to offer us an accessible and engaging volume that offers unique perspectives on strengths and how to develop them. They have done that well. Theoretical and methodological concerns with how strengths are conceptualised and strengths interventions conducted and evaluated belong elsewhere.

A further appeal of Character Strengths Matter is that all proceeds of book sales will go to a positive psychology student scholarship fund in memory of Chris Peterson, leading positive psychology researcher, co-creator of the VIA classification, inspirational and humorous teacher, and one of the most widely liked and respected figures in the field of positive psychology. Buy the book in honour of Chris and enjoy the new perspectives it will provide.

\author{
Author \\ Denise Quinlan \\ drdenisequinlan.com \\ denise@drdenisequinlan.com
}

\title{
Publishing Timeline
}

Received 24 July 2015

Accepted 25 July 2015

Published 30 July 2015 


\section{References}

Polly, S., \& Britton, K. H. (2015). Character Strengths Matter - How To Live A Full Life. USA, Positive Psychology News. 250 pp., US\$18.95 + US\$3.82 epub, ISBN: 0692465642, EAN-13: 978-0692465646. 